\title{
Acquisition of a jumping avoidance response in hamsters ${ }^{1}$
}

BRUCE E. SANDLER AND GEORGE G. KARAS IOWA STATE UNIVERSITY

Hamsters were found to readily acquire a jumping avoidance response, but showed no differential performance as a result of differences in shock intensity or intertrial interval. The performance of rats in an earlier experiment was superior to that of the hamsters in our study.

Avoidance conditioning has been demonstrated in a wide variety of species and apparatus. Only one study, however, has reported efficient shock avoidance conditioning in hamsters (Pearl, 1963). The Sidman avoidance response was used in this research. Recent attempts to obtain avoidance conditioning with hamsters in a shuttlebox (Ewing, 1964) and in a oneway avoidance situation (Williams, 1963) have not been successful. Babbini \& Davis (1967) have reported difficulty in obtaining an avoidance response with hamsters in a square four-compartment box. They report obtaining $9.48 \%$ avoidance responses for hamsters as compared to $61.57 \%$ avoidance responses for Holtzman rats in the same experimental situation (Davis, Babbini, \& Huneycutt, 1967). Williams (1963) compared the acquisition of an avoidance response in golden hamsters and Wistar albino rats in a oneway avoidance situation. A tone served as the CS and the animals were run a total of 50 trials. The percentage of avoidance responses was $16.8 \%$ for the hamsters and $55.2 \%$ for the rats. As in the Babbini \& Davis (1967) study, the escape latencies showed a marked decline over time.

In view of the hamster's predilection toward climbing it was felt that the procedure described by Baum (1965) might be useful in obtaining avoidance conditioning. Pilot work indicated that an avoidance response was readily, and rapidly, acquired in this apparatus. The effects of intertrial interval (ITI) and shock intensity on the acquisition of an avoidance response have been repeatedly demonstrated-(Murphy \& Miller, 1956; Levine \& England, 1960; Brush, 1962; Kimble, 1955; Trabasso \& Thompson, 1962; Moyer \& Korn, 1964). For this reason, it was decided to investigate the effects of these variables on the acquisition of the response.

Nethod

The apparatus used was of the type described by Baum (1965). It was constructed of $3 / 4$ in. unpainted plywood and measured $8 \times 8 \times 12$ in. (interior dimensions). A grid floor constructed of brass rods $1 / 8$ in. in diameter, at intervals of $1 / 4 \mathrm{in.}$ on center, was placed $2-1 / 4$ in. above the bottom of the box. At a height of $3-5 / 8$ in. above the grid floor a slot was cut to accommodate the safety ledge. The ledge was constructed of a single piece of $1 / 2$ in. plywood which was painted flat black. Six shallow grooves were cut into the upper surface of the ledge to facilitate Ss' climbing onto it. A $1 / 8$ in. brass bar was placed above the ledge and 1/16 in. away from the wall. This bar prevented $S^{\prime}$ 's feet from being jammed between the ledge and the slot through which it slid. The ledge was retracted from the apparatus manually and returned by two springs mounted on the outside of the box. The top of the apparatus was transparent Plexiglas. The latencies of escape and avoidance responses were timed by a Hunter Model 120A Klockounter. The Klockounter was started automatically with the reappearance of the ledge in the apparatus, and was stopped manually when an avoidance or escape response occurred. Avoidance and escape responses were operationally defined as occurring when $S$ had both hind feet off the grid floor and was in the process of climbing onto the ledge. A constant current high voltage shock source was used.

Forty male Golden Syrian hamsters, purchased from Con Olson, Inc., Mt. Horeb, Wis., were randomily divided into four groups of 10 animals each and run in a random order. A 2 by 2 factorial arrangement was used. All Ss were approximately 100 days old. The Ss were not habituated to the apparatus.

On the first trial $S$ was dropped to the grid floor of the apparatus, and the timing equipment was turned on. Ten sec later the shock $(0.2 \mathrm{~mA}$ or $0.5 \mathrm{~mA})$ came on and remained on until $S$ escaped by climbing onto the safety ledge. The Ss were allowed an ITI of either 25 or $50 \mathrm{sec}$ on the ledge. At the end of the ITI the ledge was retracted, dropping $S$ to the grid and beginning the next trial. If $S$ fell off the ledge during the ITI the next trial began immediately. The interval available for avoiding the shock (corresponding to a CS-US interval) was $10 \mathrm{sec}$ throughout the experiment. All Ss were given 40 consecutive trials.

\section{Resulis and Discussion}

All Ss acquired the avoidance response rapidly. Analyses of variance for total number of avoidances, latency of avoidances, and differences in the rate of learning revealed no significant shock or ITI effects. No interactions were significant. The trials effect in the latency analysis, the only analysis that looked at trials, was significant $(p<.01)$, confirming the presence of conditioning. The $F$ ratio for the between Ss error term, although significant $(p<.05)$, was of a magnitude which indicated little between $S$ variation. 
The procedure was, therefore, probably insensitive to the treatments under study. This could account for the failure of the variables significantly to affect performance.

The mean number of avoidance responses was 25.13. A direct comparison of these results with those of Baum (1965) is difficult because of differences between the experiments. His animals (rats) were run until they reached a criterion of 10 consecutive avoidances. The mean number of shocks to criterion was $4.7(\mathrm{SD}=2.31)$; the mean number of trials to criterion was $6.0(\mathrm{SD}=3.51)$. It is clear that the rats acquired the response more rapidly. A comparison of the results of this study with those of Davis, Babbini, \& Huneycutt (1967) indicates that the hamsters acquired the avoidance response at least as efficiently as the rats $(62.82 \%$ avoidances for the hamsters vs $61.57 \%$ for the rats). These results reemphasize the importance of the response required of $S$ in the experimental situation.

It is possible to question the use of the Baum apparatus on the grounds that there is no clearly specifiable $C S$ and that $S$ is learning to fear being on the grid rather than reacting to a distinct warning of imminent shock. It should be recognized that the CS in this apparatus is a complex series of events consisting of the retraction and reappearance of the safety ledge, and the dropping of $S$ to the grid. Because the CS is not unitary, it is not amenable to unequivocal analysis. It is possible that instead of responding to a previously neutral stimulus $S$ is responding to being on the grid floor. If this is the basis for the response, the observed behavior is not avoidance learning in the usual sense, for the usual definition of avoidance learning requires the avoidance response to be made to a formerly neutral stimulus. Additional research is necessary to determine what aspect or aspects of the situation $S$ is responding to.

References

BABBINI, M., \& DAVIS, W. M. Active avoidance learning in hamsters. Psychon. Sci., 1967, 9, (3), 149-150.

BAUM, M. An automated apparatus for the avoidance training of rats. Psychol Rep., 1965, 16, 1205-1211.

BRUSH, F. R. The effects of intertrial interval on avoidance learning. J. comp. physiol. Psychol., 1962, 55, 888-892.

DAVIS, W. M., BABBINI, M., \& HUNEYCUTT, B. D. A new apparatus for one-way locomotor avoidance conditioning without handling. Psychon. Sci. 1967, 8, 185-186.

EWING, D. R. Avoidance conditioning in two varieties of the Syrian hamster. Unpublished master's thesis, Iowa State University, 1964.

KIMBLE, G. Shock intensity and avoidance conditioning. J. comp. physiol. Psychol, 1955, 48, 281-284.

LEVINE, S., \& ENGLAND, S. Temporal factors in avoidance learning. J. comp. physiol. Psychol., 1960, 53, 282-283.

MOYER, K. E., \& KORN, J. H. Effect of UCS intensity on the acquisition and extinction of an avoidance response. J. exp. Psychol, 1964, 67, 352-359.

MURPHY, J. V., \& MILLER, R. E. Spaced and massed practice with a methodological consideration of avoidance conditioning. $J$. exp. Psychol, 1956, 52, 77-81.

PEARL, J. Avoidance learning in rodents: a comparative study. Psychol. Rep., 1963, 12, 139-145.

TRABASSO, T. R., \& THOMPSON, R. W. Supplementary report: shock intensity and unconditioned responding in a shuttlebox. $J$. exp. Psychol, 1962, 63, 215-216.

WILLIAMS, R. E. A comparative study of golden hamsters and albino rats in an avoidance conditioning situation. Unpublished master's thesis, Iowa State University, 1963. 